\title{
Editorial \\ Towards Catalysts Prepared by Cold Plasma
}

\author{
Jacek Tyczkowski *(1) and Hanna Kierzkowska-Pawlak *(i)
}

Department of Molecular Engineering, Faculty of Process and Environmental Engineering, Lodz University of Technology, Wolczanska 213, 90-924 Lodz, Poland

* Correspondence: jacek.tyczkowski@p.lodz.pl (J.T.); hanna.kierzkowska-pawlak@p.lodz.pl (H.K.-P.)

Citation: Tyczkowski, J.;

Kierzkowska-Pawlak, H. Towards Catalysts Prepared by Cold Plasma. Catalysts 2022, 12, 75. https:// doi.org/10.3390/catal12010075

Received: 2 January 2022

Accepted: 7 January 2022

Published: 11 January 2022

Publisher's Note: MDPI stays neutral with regard to jurisdictional claims in published maps and institutional affiliations.

Copyright: (C) 2022 by the authors. Licensee MDPI, Basel, Switzerland. This article is an open access article distributed under the terms and conditions of the Creative Commons Attribution (CC BY) license (https:// creativecommons.org/licenses/by/ $4.0 /)$.
Cold (non-equilibrium) plasma techniques have long been used as plasma deposition methods to create new materials, often with unique properties, which cannot be produced any other way, as well as plasma treatment methods for the sophisticated modification of conventional materials [1,2]. The possibilities in this regard are enormous, perhaps only limited by our imagination and the laws of physical chemistry, more and more often using molecular engineering and being based on molecular designs. Among the many interesting products fabricated by plasma techniques, materials with catalytic properties occupy a special place. There are many catalytic reactions, such as $\mathrm{CO}_{2}$ hydrogenation, the decomposition of volatile organic compounds, Fischer-Tropsch synthesis, or hydrogen production, which challenge chemists and chemical engineers worldwide to search for better catalysts and more effective methods for use in their preparation. Today, there is no doubt that plasma techniques pave the way for innovative solutions in this field [3,4].

Three main research areas can be distinguished in the field of cold plasma techniques involved in the preparation of catalysts. The first particularly important approach, which opens up broad perspectives, is the plasma deposition of entirely new, advanced catalytic materials with defined molecular structures and nanostructures, using a wide range of volatile organic or organometallic precursors in this process (often referred to as plasmaenhanced chemical vapor deposition (PECVD)). One of the main advantages of this type of catalytic material is their thin-film nature (thickness from a few nanometers to several micrometers) and their ability to be deposited on supports of virtually any shape without changing their original geometry, which is extremely useful in the construction of a new generation of structured chemical reactors [5].

The second area of interest is the use of cold plasma in the conventional production of catalysts, both via plasma interaction during catalyst formation and via controlled plasma surface modification of a catalyst that has already been conventionally prepared. Such plasma treatment can replace the thermal calcination process, modify a catalyst's nanostructure (for example, its dispersion and particle sizes), reduce or oxidize the surface of a catalyst, immobilize catalytic species on supports, and so on. In many cases, we have already been able to select the parameters of the plasma treatment process in such a way as to significantly improve the efficiency and selectivity of conventional catalysts [6].

Recently, as the field of plasma catalysis began to develop intensively [7], in which catalytic processes are carried out over conventional catalysts, but in a plasma environment, a third research area emerged regarding the effect of plasma on the catalyst used. Although this problem resembles the above-mentioned plasma modification of the surface of a conventional catalyst, in this case, we do not control the parameters of the plasma treatment but only passively observe how the plasma with optimized parameters for the plasma catalysis process is affecting our catalyst. This process may also degrade the activity of the catalyst, rather than improve it [8].

In this Special Issue, all three research areas that deal with the involvement of cold plasma in the preparation of catalysts are addressed.

Two papers prepared by our team from the Lodz University of Technology (Department of Molecular Engineering) are strictly related to the production of new thin-film 
catalysts using the PECVD method. The first [9] presents a new type of thin films based on cobalt and iron oxides produced by plasma co-deposition from a mixture of organometallic Co and Fe precursors, the ratio of which controlled the composition of the prepared films. The films were tested using the $\mathrm{CO}_{2}$ to $\mathrm{CO}$ hydrogenation process. Their catalytic activity was shown to be substantially higher compared to "pure" CoOx-and FeOx-based films, which was attributed to the likely formation of $\mathrm{p}-\mathrm{n}$ junctions between iron and cobalt oxide nanoparticles.

The second paper [10] is devoted to thin plasma-deposited NiOx-based catalytic films that were tested using the $\mathrm{CO}_{2}$ methanation process. A very important conclusion emerges from this work, namely that the active phase in the tested films is $\mathrm{Ni}_{2} \mathrm{O}_{3}$, contrary to the popular opinion that this phase is metallic nickel. In addition, in this case, metallic nickel even quenches the catalytic activity. As can be seen, the plasma deposition of catalytic films reveals many new and intriguing effects.

The next two papers in this Special Issue deal with the involvement of cold plasma in the conventional production of catalysts. In both cases, dielectric barrier discharge (DBD) treatment was used in the process of forming the catalytic material from the inorganic precursor with which the supports were impregnated. Thus, an increase in catalytic activity was obtained in comparison to the catalyst without plasma treatment.

In this way, $\mathrm{Fu}$ et al. [11] produced a $\mathrm{RuO}_{2} / \mathrm{Sn}_{0.2} \mathrm{Ti}_{0.8} \mathrm{O}_{2}$ catalyst for chlorinated volatile organic compound degradation. They found that the plasma treatment was the main factor that determined the excellent improvement of catalytic efficiency compared to the catalyst produced via conventional calcination. It was associated with an increase in the specific surface area and increased Ru species dispersion, and Ru was obtained at a higher oxidation state than +4 .

In turn, $\mathrm{Liu}$ and Ye [12] produced a catalyst based on $\mathrm{Si}-\mathrm{W}$ on $\mathrm{SiO}_{2}$ and $\mathrm{Al}_{2} \mathrm{O}_{3}$ supports, impregnating them with silicotungstic acid and then treating some of them in Ar or air plasma. The obtained catalysts were tested in the process of glycerol dehydration to acrolein. A limited improvement in the conversion of glycerol and the selectivity to acrolein was achieved for the catalyst after Ar plasma treatment. This could be due to the change in the ratio of the relative amount of Brønsted acid sites to Lewis acid sites on the catalyst surface, which was decreased for Ar-plasma-treated samples.

The last of the four papers deals with the problem of changing the structure and properties of catalysts exposed to plasma during plasma-catalytic processes. Two of the papers, prepared by Govender et al. $[13,14]$ from the University of KwaZulu-Natal in Durban, presented plasma-catalytic Fischer-Tropsch synthesis at very high pressure, using sequentially coated $\gamma-\mathrm{Al}_{2} \mathrm{O}_{3}$ and then applying cobalt onto a mullite support as a catalyst. These studies revealed strong plasma-catalyst interactions that resulted in a more uniform Co dispersion and possibly the reduction in the ratio of cobalt oxides to metallic cobalt, in this case enhancing the catalytic properties of the Co-catalyst surface.

The other two publications that reported the behavior of catalysts under plasma catalysis conditions were created by a joint team from the Warsaw University of Technology and the Military University of Warsaw. Woroszył-Wojno et al. [15] discussed the decomposition of toluene, which was a model substance for tars, performed using a gliding discharge reactor and a new $\mathrm{Ni}_{3} \mathrm{Al}$ system in the form of a honeycomb as a catalyst. Although several changes in the composition of the catalyst surface were observed as a result of the plasma-catalysis process, these changes were not shown to have an effect on the toluene conversion. In turn, Ulejczyk et al. [16] presented interesting results on the plasma-catalytic hydrogen production from a mixture of methanol and water in a spark discharge reactor using metallic $\mathrm{Ni}$ on $\mathrm{Al}_{2} \mathrm{O}_{3}$ as a catalyst. Although the process is carried out in the "remote plasma" mode and, for example, no changes in the Ni dispersion were observed, some differences between the surface of the fresh and the used catalyst were revealed here. A promising result is the oxidation of some part of Ni by plasma. The presence of nickel oxide can be advantageous because it makes photochemical reactions involving light emitted by plasma run more efficiently. 
The publications collected in this Special Issue already sufficiently prove the wide possibilities that cold plasma techniques have, both in the production of completely new thin-film catalytic materials and the modification of conventional catalysts. Therefore, we encourage further research in this field, which will undoubtedly lead, on the one hand, to significant progress in basic sciences, and, on the other hand, provide attractive catalytic systems for advanced technologies.

We sincerely thank all of the authors for their valuable contributions, as well as the editorial team of the Catalysts, especially Mr. Sonic Zhao, for their support.

Author Contributions: The contribution of J.T. and H.K.-P. is equal. All authors have read and agreed to the published version of the manuscript.

Funding: This work was financially supported by the National Science Centre (NCN) of Poland (Dec. 2017/25/B/ST8/00969).

Conflicts of Interest: The authors declare no conflict of interest.

\section{References}

1. Inagaki, N. Plasma Surface Modification and Plasma Polymerization; Technomic: Lancaster, PA, USA, 1996.

2. Biederman, H. Plasma Polymer Films; Imperial College Press: London, UK, 2004.

3. Tyczkowski, J. Cold Plasma produced catalytic materials. In Plasma Science and Technology—Progress in Physical States and Chemical Reactions; Mieno, T., Ed.; InTech Open: Rijeka, Croatia, 2016; pp. 53-93. [CrossRef]

4. Wang, Z.; Zhang, Y.; Neyts, E.C.; Cao, X.; Zhang, X.; Jang, B.W.-L.; Liu, C. Catalyst preparation with plasmas: How does it work? ACS Catal. 2018, 8, 2093-2110. [CrossRef]

5. Tyczkowski, J.; Kierzkowska-Pawlak, H.; Kapica, R.; Balcerzak, J.; Sielski, J. Cold plasma—Promising tool for the production of thin-film nanocatalysts. Catal. Today 2019, 337, 44-54. [CrossRef]

6. Liu, C.; Zou, J.; Yu, K.; Chen, D.; Han, Y.; Zhan, J.; Ratanatawanate, C.; Jang, B.W.-L. Plasma application for more environmentally friendly catalyst preparation. Pure Appl. Chem. 2006, 78, 1227-1238. [CrossRef]

7. Bogaerts, A. Editorial Catalysts: Special issue on plasma catalysts. Catalysts 2019, 9, 196. [CrossRef]

8. Zhang, S.; Oehrlein, G.S. From thermal catalysis to plasma catalysis: A review of surface processes and their characterizations. $J$. Phys. D Appl. Phys. 2021, 54, 213001. [CrossRef]

9. Kierzkowska-Pawlak, H.; Ryba, M.; Fronczak, M.; Kapica, R.; Sielski, J.; Sitarz, M.; Zając, P.; Łyszczarz, K.; Tyczkowski, J. Enhancing $\mathrm{CO}_{2}$ conversion to $\mathrm{CO}$ over plasma-deposited composites based on mixed Co and Fe oxides. Catalysts 2021, 11, 883. [CrossRef]

10. Smolarek, M.; Kierzkowska-Pawlak, H.; Kapica, R.; Fronczak, M.; Sitarz, M.; Leśniak, M.; Tyczkowski, J. Cold plasma synthesis and testing of $\mathrm{NiO}_{X}$-based thin-film catalysts for $\mathrm{CO}_{2}$ methanation. Catalysts 2021, 11, 905. [CrossRef]

11. Fu, Y.; Zhang, Y.; Xin, Q.; Zheng, Z.; Zhang, Y.; Yang, Y.; Liu, S.; Zhang, X.; Zheng, C.; Gao, X. Non-thermal plasma-modified Ru-Sn-Ti catalyst for chlorinated volatile organic compound degradation. Catalysts 2021, 10, 1456. [CrossRef]

12. Liu, L.; Ye, X.P. Nonthermal plasma induced fabrication of solid acid catalysts for glycerol dehydration to acrolein. Catalysts 2021, 11, 391. [CrossRef]

13. Govender, B.B.; Iwarere, S.A.; Ramjugernath, D. Plasma-catalytic Fischer-Tropsch synthesis at very high pressure. Catalysts 2021, 11, 297. [CrossRef]

14. Govender, B.B.; Iwarere, S.A.; Ramjugernath, D. The effect of cobalt catalyst loading at very high pressure plasma-catalysis in Fischer-Tropsch synthesis. Catalysts 2021, 11, 1324. [CrossRef]

15. Woroszył-Wojno, J.; Młotek, M.; Perron, M.; Jóźwik, P.; Ulejczyk, B.; Krawczyk, K. Decomposition of tars on a nickel honeycomb catalyst. Catalysts 2021, 11, 860. [CrossRef]

16. Ulejczyk, B.; Nogal, Ł.; Jóźwik, P.; Młotek, M.; Krawczyk, K. Plasma-catalytic process of hydrogen production from mixture of methanol and water. Catalysts 2021, 11, 864. [CrossRef] 